\title{
A blended learning approach for teaching python programming language: towards a post pandemic pedagogy
}

\author{
Mouenis Anouar Tadlaoui ${ }^{*}$ and Mohammed Chekour ${ }^{2}$ \\ Abdelmalek Essaâdi University, Faculty of Sciences, Tétouan, Morocco ${ }^{1}$ \\ Abdelmalek Essaâdi University, Ecole Normale Supérieure, Tétouan, Morocco²
}

Received: 12-December-2020; Revised: 25-January-2021; Accepted: 27-January-2021

(C)2021 Mouenis Anouar Tadlaoui and Mohammed Chekour. This is an open access article distributed under the Creative Commons Attribution (CC BY) License, which permits unrestricted use, distribution, and reproduction in any medium, provided the original work is properly cited.

\begin{abstract}
Blended learning has generated remarkable interest in educational research. This interest is being concentrated increasingly throughout the Covid-19's duration. Indeed, this teaching method combines both, presential and distance learning. This teaching method's philosophy is quite simple. it aims to exploit the qualities of the mentioned two teaching modes. However, the usage of Blended learning isn't sufficiently advanced as it causes genuine issues in the educational scripting of the instructive substance. In this research, it is an aim to concretize this philosophy in a fairly complicated course, as well as an advanced level: Python programming language for students of preparatory classes. To achieve this goal, a developed a personalized course model using Bayesian networks capable of helping educators in their teaching practices in addition to their students' cognitive processes is presented, as well as actualizing this model in a course creation application. Moreover, the Python programming was tested with various understudies with various degree of aptitude in the subject educated. The results presented in this paper, shows the effectivity of this approach in teaching complex course especially during the COVID19 period, based on both the satisfaction rate and the success rate metrics that was chosen to asset the following approach.
\end{abstract}

\section{Keywords}

Blended learning, E-learning, COVID19 pedagogy, Python, Bayesian networks, LMS-LD, E-learning personalization, Learning approaches, Learner model, Learner profile.

\section{Introduction}

We are social beings, we depend on shared actions, various types of interactions with others. With the current pandemic, a breakdown in the social fabric is associated with several stressors that can negatively affect people's mental health [1]. In this situation, people have changed their behaviors by adopting social distancing measures. Indeed, humanity is threatened by a global pandemic. The latter can last as long as a vaccine or an effective medicine is not found. Vision is not clear and the stress caused by this pandemic is releasing "negative" chemicals into our brains. Furthermore, it is more than necessary to produce beneficial activities to affect the reward zone in our brain. In this context, school is a real environment of beneficial actions based on human interactions [2].

*Author for correspondence

13
However, the emergence of Covid-19 has disrupted all facets of daily life around the world. Everywhere around the world, Morocco is no exception, education was one of the sectors that were harshly hit by the closure of schools: the distance is needed as the only operational solution to save the current situation. As a result, education in Morocco is experiencing a real challenge due to the consequences of covid19. This challenge has materialized in the transformation of the face-to-face, presential, teaching mode into distance learning [3]. Additionally, there has been little pedagogical consistency in how this change has occurred. Months later, the national education ministry adopted "Blended Learning" in all educational cycles when the schools partially reopened. This emergency plan caused several problems for learners, teachers and policy makers. Indeed, a change of this magnitude requires technological prerequisites for learners and techno-pedagogical prerequisites for teachers.

The following research will be focusing on teaching computer science, and more specifically 
programming in python. The choice of python is not arbitrary. In the programming world, Python is increasingly the most answered, as well as, the most popular. However, students are not interested in pursuing their studies in this field. The sources of this problem are diverse. Students encounter psychological, epistemological and didactic problems.

As part of this research, the didactic obstacles will also be explained. The existence of several pedagogical approaches to teaching python is an advantage that cannot be neglected. Nevertheless, this diversity makes the teacher's job progressively complicated. Indeed, each teaching approach has its advantages and disadvantages.

According to computer educators, the investigative approach, the problem-solving approach, the trial / error strategy will only be beneficial during the construction of programming knowledge. The challenge is to take advantage of these approaches to promote an effective and upbringing learning; That is why a "handy" solution was adopted for teachers in the form of an educational scenario. The following work is based on the scenario that integrates the most appropriate pedagogical approaches for teaching and learning programming concepts. Also, the scenario takes into consideration the importance of group work (the collaborative dimension) in addition to the constraints generated by the pandemic and social distancing (blended learning).

\section{Literature review}

In this section, it Is a must present the literature review on the impact of COVID-19 on the education sector, along with the pedagogical innovation needed to suit the change in that sector. Moreover, in this research, the literature review for teaching python using different didactical approaches will be presented.

\subsection{Towards a post pandemic pedagogy}

As a start of this section, the context of our research, the rise of blended learning as a method that would respond to the changes that the world is witnessing due to the COVID19 pandemic. Likewise, the relevant work on the innovation in teaching programming language in general and Python specifically.

\subsubsection{The impact of COVID19 on education}

The current pandemic has shaken educational systems around the world. Therefore, it represents a huge challenge to it. Likewise, the COVID19 epidemic has a huge implication on educational institutions. The time of the corona virus recession is unclear. As a result, there is uncertainty over how long the coronavirus crisis will last. Throughout COVID19, Crawford [4] described the response of several schools in 20 countries and demonstrated diverse responses to this complex challenge. The reaction to the current challenge has enabled elearning via live streaming on Facebook, YouTube, Google Classrooms, Zoom, also, via the e-learning platforms.

The responses of Arab countries to the risk of coronavirus have the potential to exacerbate some of the problems already encountered [5]. In Morocco, the government announced on March 17, 2020, the closure of all universities, schools and private establishments due to the global effect of the "corona virus". Due to these circumstances, the Minister of Education stated that the only working solution is elearning. Also, the Ministry of National Education has categorically denied having announced "a blank year". The ministry stressed that the rest of the program for the other levels will be completed in the next school year, with the 4-5-week gaps to be completed. Many students are suffering from this closure; however, some private colleges have taken steps to complete their education online [6].

During the lockdown, some teachers recorded and uploaded their lessons online for students to access and some were even more innovative and used elearning platforms, but most teachers are not ready to manage online education. As for the learners, the situation is more dramatic: the majority of these have found major difficulties in accessing, assisting, participating in and completing the homework assigned by their teachers. However, basic computer skills and those related to information processing are considered necessary for any online training. Thus, in a distance training action, the first criterion for success is the ability to communicate with the technological tool [7].

2.1.2Blended learning approach

Blended learning combines the best elements of traditional training with those of distance training. Formally, the integration of ICT into the Moroccan education system is an extremely ambitious task, whether at school level or for the entire education system. This integration can overcome several educational challenges. The constraints of COVID-19 are just one example. Blended learning is a combination of traditional teaching methods (face to face) and online teaching based on learning 
platforms. Learning in the classroom promotes human interaction while online learning allows the learner to plan in time and space their student activities and the pace of learning. However, it is for the teacher to decide which educational elements should be discussed in the class or online [8]. The philosophy of this learning mode is quite simple: to focus on the advantages of face-to-face and distance education. Analysis of testimonies and experiences in blended learning provides details on student response, teacher attitudes and parents' opinions. It also shows how these models have become increasingly rich, which makes this mode of learning very encouraging. However, avenues for future development are suggested, especially in terms of the pedagogical approaches adopted for this new method of teaching [9].

The universe of blended learning began uncertainly amid overt resistance from traditionalist teachers. The source of this resistance is quite complicated. Yet, the analyses of teachers' beliefs have long played a role in explaining their digital behaviors, as demonstrated by in-depth qualitative [10] and quantitative [11] analyses, the study by these factors did not result in any substantial change in their beliefs. Certainly, the current COVID-19 pandemic that has shocked the entire world can also help to change the opinion of these teachers and those involved in this new mode of teaching. To put in a nutshell, technology skills have become essential skills for the current and future educators.

2.1.3Approaches to teach Python programing language The educational approaches are diverse. In the literature field, the approach is represented by objectives, skills, problem solving, project and, investigation. Each has its own advantages. Teachers of programming generally and python particularly are invited to find the most appropriate recipe to transmit and build new knowledge and skills to the learners [12]. From these approaches follow a set of methods and techniques to promote learning. Unfortunately, there is neither an obvious solution nor a magical wand to make learning more effective and sustainable. However, experiments and methods have given promising clues. The study and analysis of these experiences will only be beneficial in helping to improve the current situation [13] Some authors suggest research to test different pedagogical approaches [14]. Yet, the diversity of educational aspects complicates the analysis of the different approaches of the educational programming.
To illustrate, Bruce [15] argues that there is a need for additional and experimental research to explore the different pedagogical approaches of the teaching program.

Researchers suggest using "feedback" to obtain a better result [16]. This strategy focuses on learners' errors, in order to build their scientific knowledge. Still, this method, based on the pedagogy of error, is quite painful for the teachers as it contains elements of individual learning that are costly in terms of time. Other researchers argue that a reform is needed in the teaching of the Python programming language: The methods of training and assessment of the examination system are an urgent problem of the proposed reform [17]. According to Begosso, Python is designed to optimize the productivity of programmers by offering high-level tools and an easy-to-use syntax $[18,19]$. The resource richness of the open community also poses new challenges, a large amount of information will require a lot of attention [20]. Kui propose a "Mode of teaching by visualization: visualization teaching mode". By dynamically adjusting the curriculum, scientifically planning educational content, and effectively using appropriate educational approaches, the quality of teaching can be improved [21]. From another perspective based on the learning pyramid and retention rate, Fagan and Payne consider that the best way to learn python is to teach it [22].

2.1.4The proposed educational scenario in blended learning mode

There are two scenarios: the teaching scenario and the learning scenario. The first describes the teacher's role in tutoring and coaching. The second describes the learner's activities. The teacher suggests ways of building knowledge to teach. For instance, broadcasting explanatory videos accompanied by problems to progress in the appropriation of the concepts in question. The intervention of the teacher will only take place in the "block" during the learning process. Indeed, the teacher encourages his initiatives in solving problems, considering the "Error" as an important step in the construction of new knowledge. Learners are encouraged to consult and discuss with their peers the content disseminated by the teacher, so they can commit to solve the problems suggested by the instructor. Students work in small groups to promote sharing, discussing and collecting problems' solutions. In case the learners find it difficult to solve the problem, the teacher activates the investigative approach so that the learners themselves find the error to correct it. 


\section{Methods}

\subsection{Model implementation and experiments}

In this section of the research, it is essential to represent the experiments that are used to test the blended learning approach to teach Python programing language. First, the course model using Bayesian networks. Second, the way in which the previous model will be implanted in an adaptive created course application. Finally, the research will submit the assessments that the approach will take to test the different hypothesis.

3.1.1Budling a blended course model using Bayesian networks

To represent in a dynamic way the learning path that each learner will follow during the Python training using the Blended learning approach, Bayesian networks is chosen as a probabilistic work frame [23] to represent our course model "Figure l".

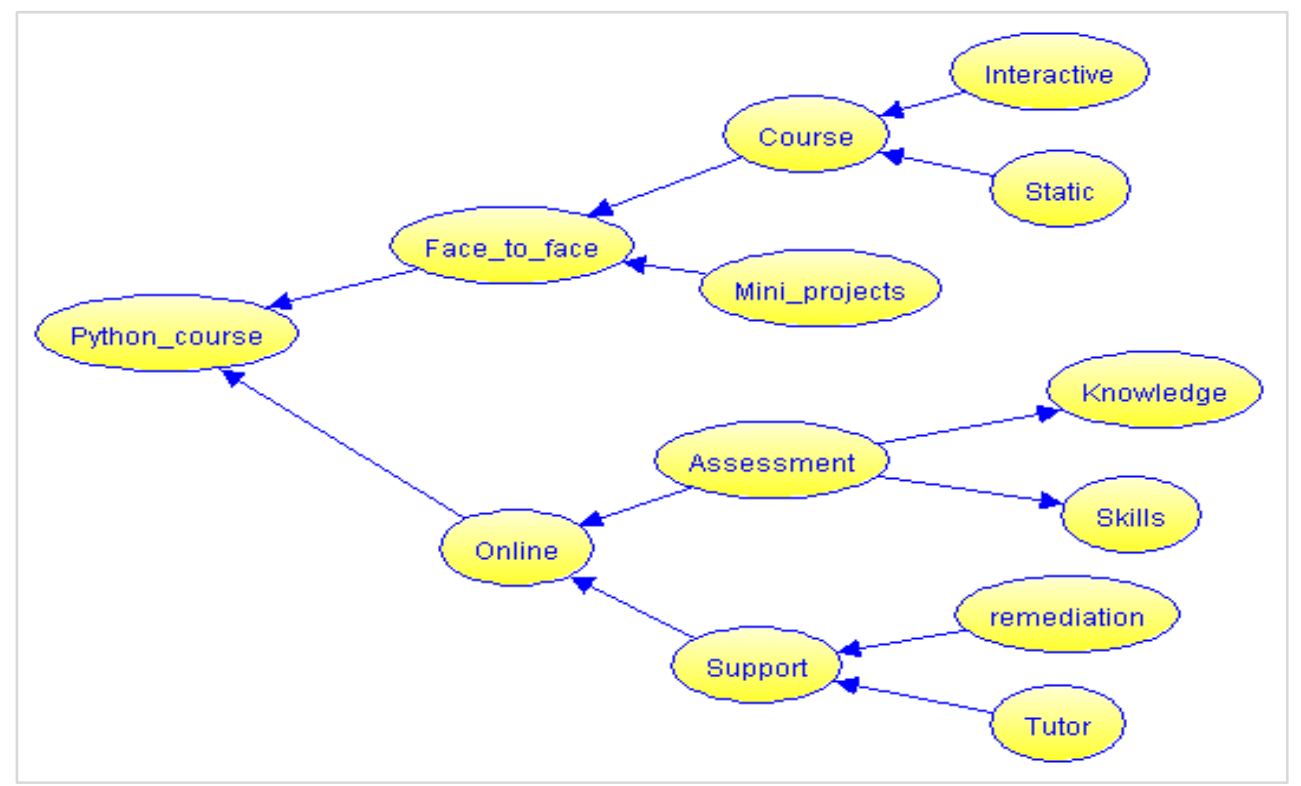

Figure 1 Bayesian network of Python blended course model

3.1.1.1Structure specification of the Model

Before diving to illustrating the stages of development of Bayesian networks to model the initial tests for the collection of data on the learner, it is a necessity to define the nodes of the network used. The network used in this examination consists an initial "Python Course" node, which is composed of two parent nodes representing the face-to-face and the online way of teaching; Each of these nodes is also composed of the parent nodes representing the different activities experienced in each course; the type of online assessment and the ways of support in case of remediation. the links of these nodes are preliminary relations:

The value that measures the relative importance of each condition varies from 0 to 1 , the values of each evaluation element are defined by the teacher [24]. In other words, it is the weight of the arc from the parent node to the child node. All weights regarding the child variable will build its conditional probability table (CPT). The sum of the weights of all arcs at / from each child / parent node in case of hidden variables / proofs should be 1 . This means that each weight is standardized $[25,26]$. The relationship between the target variable $(\mathrm{T})$ and the variable of the proof $(\mathrm{E})$ must be from $\mathrm{T}$ to $\mathrm{E}$ because the process that calculates the posterior probability of the target variable is evidence of diagnostic knowledge. So, if variable of evidence has no child and its parents must be target variables [27]. There are two types of relationships: Prerequisite relationships between the target variables. Diagnostic relationships of the target variables to the proof. The mastery of concepts (targets) effects on the confidence of evidence. But, if the learner has failed an exam, he is not sure of his/her lack of knowledge or ability because he can make an unexpected mistake.

3.1.1.2 Structure specification of the Model

After defining the structure of the Python course model. The following step is characterized on defining the values of each variable. In the developed Bayesian network, the "Python course" (P) consists 
of two parents: Face to Face learning (F), and Online learning $(\mathrm{O})$ corresponding to three reports of preliminary weights: $\mathrm{w} 1=0.5, \mathrm{w} 2=0.4$. The conditional probability of (I) is calculated as follows [27]:

$P(P \mid F, O)=w 1 * h 1+w 2 * h 2$

Thus:

$h 1=\left\{\frac{1 \text { if } F=P}{0 \text { otherwise }}\right.$

$h 2=\left\{\frac{1 \text { ifo }=P}{\text { o otherwise }}\right.$

It should indicate that $\{\mathrm{P}, \mathrm{F}, \mathrm{O}\}$ is a complete set of mutually exclusive variables, whose variable is also random and binary.

By generalizing on the formula below, it is that:

$P(X=1 \mid Y 1, Y 2 \ldots Y n)=\sum_{i=1}^{n} w i * h i$

Where $h 1=\left\{\frac{1 \text { if } Y i=X}{0 \text { otherwise }} \quad\right.$ With random binary
Obviously,

$P($ not $X \mid Y 1, Y 2, \ldots, Y n)=1-P(X \mid Y 1, Y 2, \ldots, Y n)$.

3.1.2The implementation of the model in a course creation application

The training path of the Python programming course consists of two major sections: the face-to-face learning that takes place in the classroom, and the online learning, that requires the use of an online platform that the learner can use to continue within his learning path.

Although several platforms can be used to test the blended approach presented in teaching Python programming language, the lack of direct communication and guidance from both the system and the tutor led to use the course creation application COPROLINE [24] to implement the course model. The architecture of the learning section of COPROLINE presented in Figure 2 shows the interaction of the collaboration systems and the production systems within the application.

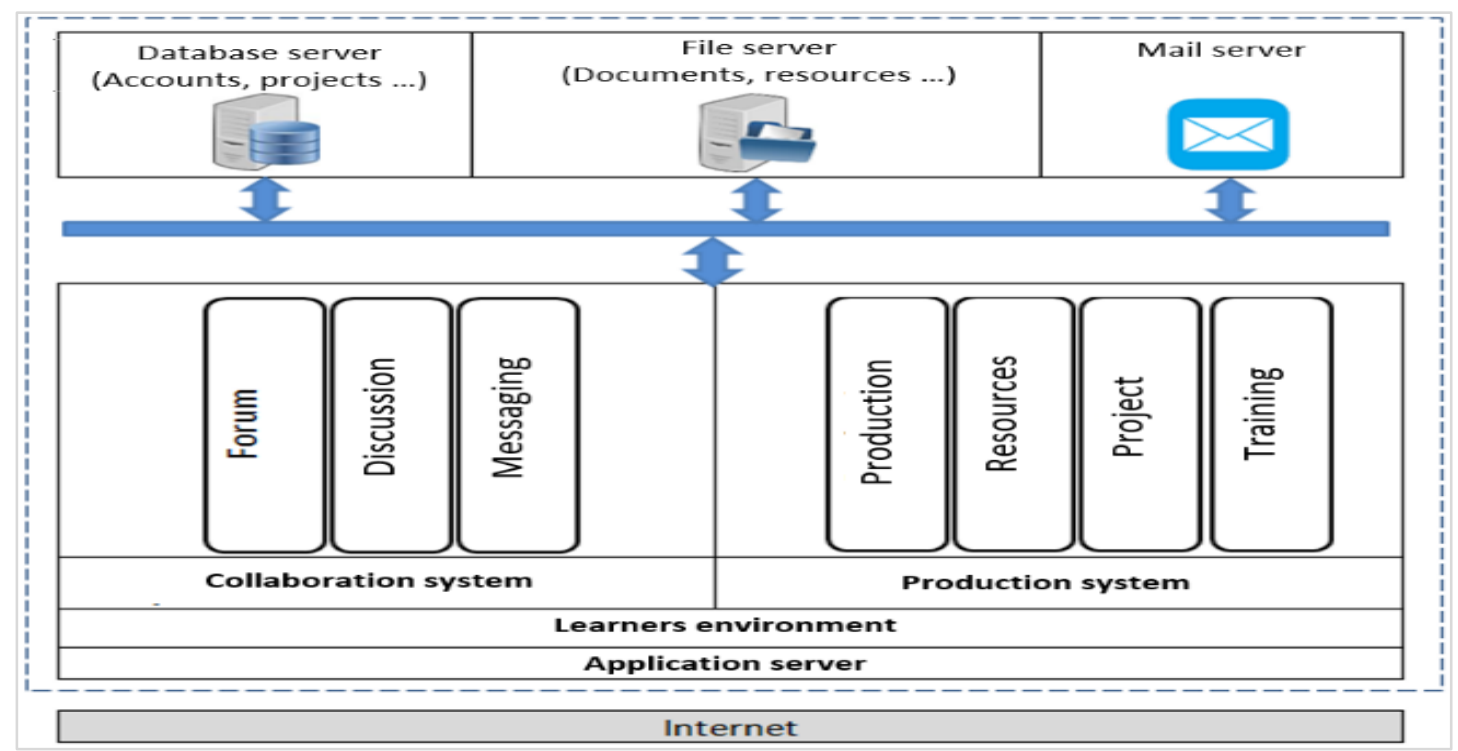

Figure 2 The general architecture of the learning section in COPROLINE [24]

COPROLINE offers to the learner the possibility of consulting the documents and resources proposed by the educators that serve to facilitate the tasks [28]. The learner also has the opportunity to participate in forums, and even to contact the teacher. The learner can chat online with the teacher / trainer as he can also edit his profile and view his results [29].
3.1.3Experiments and assessment during and after the training

To test the blended approach to teaching Python programing language training it is a need to conduct several assessments and surveys to monitor the evolution of each student during and after the training. This training had place in the "MTEducation Academy", a Private Academy of Modern 
Technology Education; Located in Tétouan, Morocco. The Academy is a leading company specialized in certifications and trainings in the field of educational science and computer science.

The result of the study that will be presented in the following section have more than 150 participants with different levels of expertise as shown in Figure 3. Initial tests have been conducted to assess their level of expertise in both the knowledge and abilities in the Python programming language These initial tests have been proposed by the teachers of the module as they have taken place online in the hypermedia system while being monitored and tracked to ensure the time frame allowed for each student to finish the task assigned to him/her.

All the participants in the previous training were divided into four levels of expertise; beginner, intermediate, advanced, and expert. With the majority of the participants in Python training with an intermediate level of knowledge in python making up $32 \%$ of the total participant of the training, $29 \%$ of the participants with an advanced level in python programming, 24\% of the participant with little or no prior knowledge in Python programming were assigned to the beginner level, and finally, $15 \%$ of the participants were assigned into the expert level after the initial assessments.

\section{Number of participants in Python training}

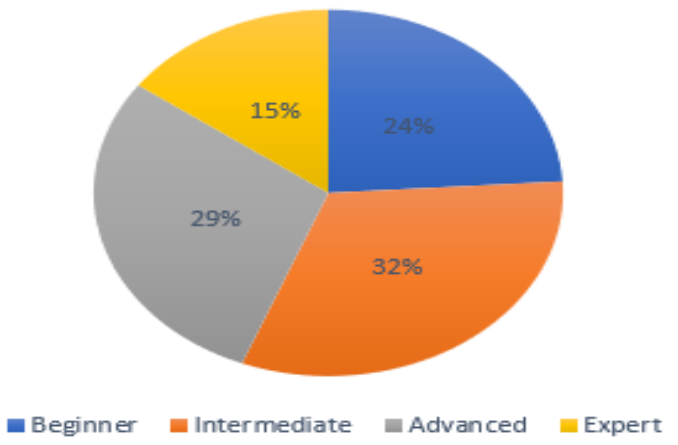

Figure 3 The number of participants in python training according to their level

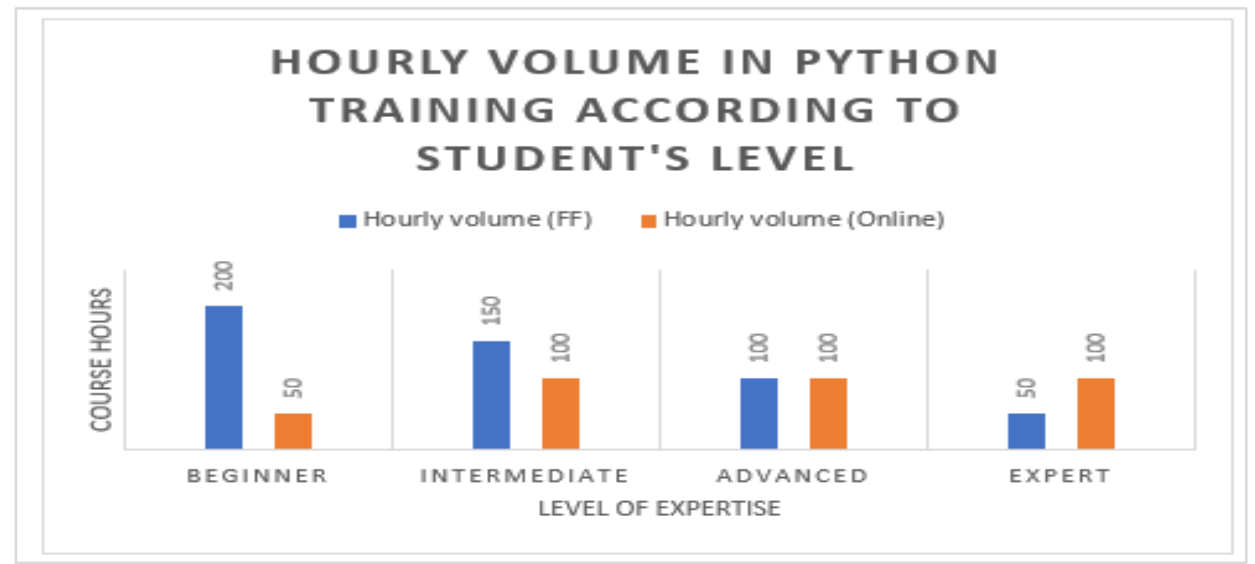

Figure 4 Hourly volume in Python training according to student's level

The hourly volume of the training is 250 hours, including the theoretical notion and structure of Python language and practical work of coding and working on mini projects for each section of the training. Dividing the hourly volume of the training between the face-to-face learning and the online learning is relevant to the level of expertise of each student as shown in Figure 4. For the beginner level, the majority of the course is being conducted using the face-to-face learning approach to ensure the acquisition of notions and syntax of the python programing language, while only 50 hours were dedicated to the evaluation of learner using the online learning approach. The number of hours augmented 
from $50 \mathrm{~h}$ to $100 \mathrm{~h}$ using the online approach with students at an intermediate level, while dedicating 150 hours using the face-to-face learning approach. For the Advanced level, the division of hours using the face-to-face and online learning approaches is done evenly with 100 hours, which sums up the total of the hourly volume in the Python training to 200 hours only. While for the expert level, only 50 hours were dedicated to the face-to-face approach, and the remaining $100 \mathrm{~h}$ were conducted using the online learning approach, with students working on mini projects related to advanced notions like Machine learning using Sklearn or Managing data with Pandas.

\section{Results}

The results of the surveys conducted on all the participants in the Python programing language training are characterized on the surveys that took place during and after the training. Starting by presenting the results of the success rate of different level of expertise using the three methods: traditional (face-to-face), the online approach and the blended learning approach. To present finally the satisfaction rate of the participant for using each of these approaches during the training.

\subsection{Student's success rate after training}

To support the approach of the use of the blended learning approach. The research states In Figure 5 the success rate in Python training using different learning approaches. A rate that is calculated based on the fraction or percentage of success among a number of attempts.

For the beginner level, the success rate of the students did not pass $50 \%$ of all participants, while only $20 \%$ of the students did pass the online evaluation. When using the blended learning approach, the percentage of the success rate augmented to almost $80 \%$ percent of the participants. For the intermediate level of expertise, the rise of success rate using the traditional approach to almost $60 \%$, for the online method, the percentage of success also augmented to more than $30 \%$. The highest percentage of success with more than $80 \%$ of the students achieving their learning goals using this method.

Although the success rate using the blended learning approach with learners in the advanced level is lower than $80 \%$, the blended learning approach success rate is still prominent than the other two learning approaches combined.

Finally, the expert level of students, represents the lowest percentage of success rate in all the learning approaches measured due to the complex notions and projects taught in the course. The success rate using the traditional approach is lower than 50\%, 30\% using the online learning approach and more than $70 \%$ using the blended learning approach which is found more suitable disregarding the level of expertise of the participants in Python training.

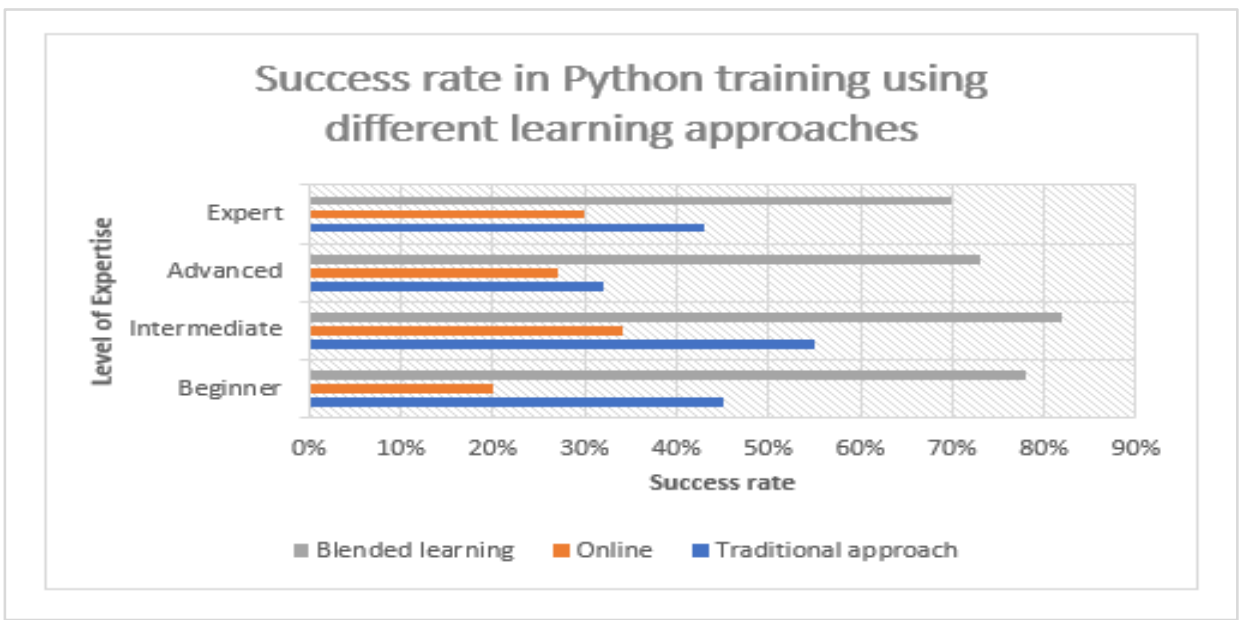

Figure 5 Success rate in Python training using different learning approaches 
4.2Student's Satisfaction rate after training Another argument to support the hypothesis of using the blended learning approach as a framework to teaching Python programming language is the training satisfaction survey which was conducted during and after the training to measure the response of the participant to the three approaches as illustrated in Figure 6.

For the beginner level, the satisfaction rate, according to the survey conducted was $45 \%$ for the online approach, 55\% for the traditional approach and $90 \%$ for the blended learning approach. As for the intermediate level, the satisfaction rate was higher. With $70 \%$ for the traditional approach, $48 \%$ for the online approach and $88 \%$ for the blended learning approach. The highest satisfaction rate for the traditional and the blended learning approaches was in the advanced level of expertise with $72 \%$ for the first and $95 \%$ for the latter and with only $45 \%$ for the online approach. As for the expert level, the online approach was the least satisfactory with only $30 \%$ satisfaction rate. Also, the satisfaction rate of using the traditional approach only dropped to $50 \%$, while the blended learning approach recorded $90 \%$ of satisfaction rate among participants with expert level in Python.

There are other parameters to test the hypothesis, such as, testing in real world project using python, or testing the success rate within a large scale of students in different field of studies. Limiting the parameter presented in this paper to the success rate and satisfaction rate while testing the three approaches presented to cover both the knowledge and human side of training a programming language such as python.

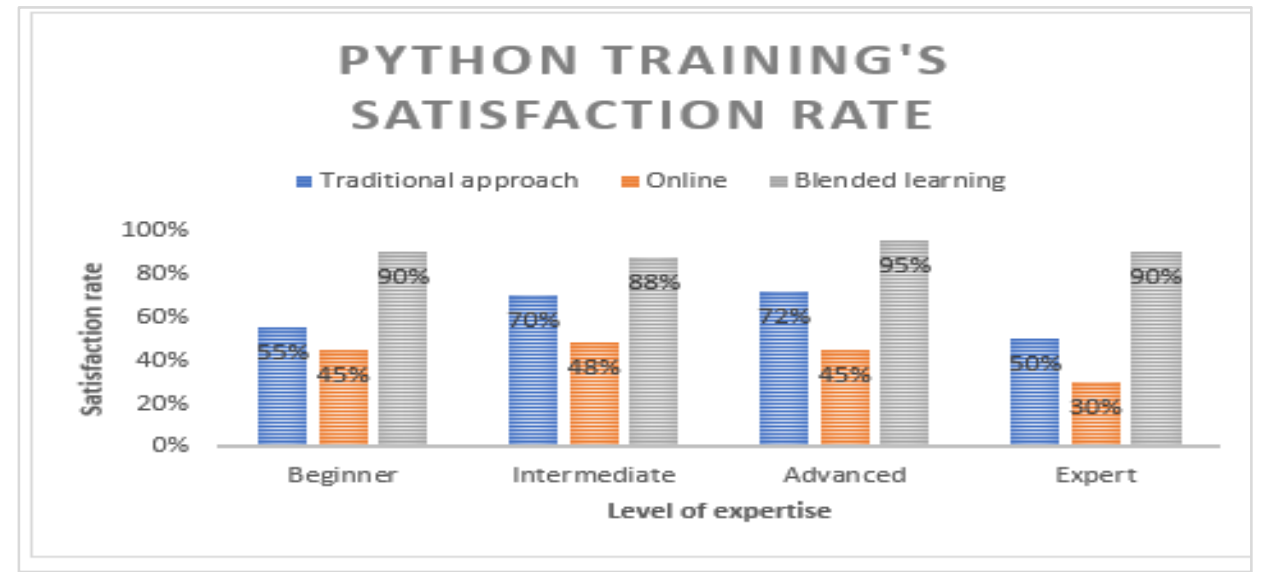

Figure 6 Python training student satisfaction rate, according to different learning approaches

\section{Discussion}

The three gates presented in this paper are the main methods in which python course and most of computer science courses are taught. Although the traditional method or the face-to-face method is used in most universities, the blended learning methods show effectiveness in both the student satisfaction, and the success rate in the subject taught. For the online methods which are used wildly during the COVID-19 pandemic, there are many limitations to its use especially with an expert level of knowledge.

Based on the results that were presented in the previous section; it is a must to deduct that blended learning approach is ideal for teaching Python programing language and any other computer science course is based on abilities (coding in this example) 20 more than knowledge. The use of the blended learning approach has a major effect on both the success rate of the students and their capacities of learning and passing the final test The students can acquire new concepts and notions, in order to apply them in mini projects.

Based on the results presented, blended learning provides educators with an additional platform to apply new teaching strategies and it is imperative that the future teachers develop such capacities and skills for independent and lifelong learning. Educators can then cultivate these same abilities and skills for their students in schools.

Although the success rate differs depending on the level of expertise in the course program, the results 
given in this paper are consistent with a higher success rate with the usage of blended learning approach. Mixing both the traditional and the online approach bring different capacities within the learners. Implementing the course model that respond to the dynamic side of the learner (the learner knowledge and abilities grows within the training) within the hypermedia system. The major problem that learners face while using online system is the lack of communication and guidance from the tutor.

Moreover, in blended learning; the blending includes not only technology, but also real-life experiences. As the word implies, it is a mix of instructor-led instruction via interactive face-to-face session, webbased assessments through feedback, reflection, results, computer-assisted instruction, i.e., digital, visual, e-learning and print instructions using traditional study materials.

\section{Conclusion and future work}

Blended learning widens the field of possibilities and helps students acquire the skills they need to develop in the 21st century. Admittedly, the dramatic escalation due to the new coronavirus shifts the world-wide education strategy towards online education. This shift has several negative effects. The research presented tends to prove that blended learning can have substantial positive effects on students, teachers, exchanges within the family and parental involvement. As the Economic progress can result from direct job creation in the technology industry as well as the development of a more qualified workforce.

The studies conducted in this paper indicate the effectiveness of the blended learning approach, there are some limitations to adopting this approach, that teacher training did not adequately prepare instructors to teach with technology. In order to successfully implement this, it is suggested that teacher training systems should incorporate the content, pedagogy and technology. In addition, most of the research, providing evidence on the merits of blended learning has focused on the merits of online learning rather than comparing face-to-face and online activities. Assessing the quality of blended learning experiences was and still not easy, as technologies generally only support part of the learning processes that students engage in.

It is planned to keep digging into this approach by conducting a large-scale study to test the effectivity of blended learning on different subjects of computer science and other educational fields. As there will be a future work, a machine learning algorithm, based on this blended approach to help creating routines for children with autism.

\section{Acknowledgment}

We like to thank Edutech Academy Tétouan and MTEudcation Academy Privé Tétouan for helping us testing our approaches and providing us with the data necessary for our research.

\section{Conflicts of interest}

The authors have no conflicts of interest to declare.

\section{References}

[1] Idrissi AJ, Lamkaddem A, Benouajjit A, El Bouaazzaoui MB, El Houari F, Alami M, et al. Sleep quality and mental health in the context of COVID-19 pandemic and lockdown in Morocco. Sleep Medicine. 2020; 74:248-53.

[2] Samlani Z, Lemfadli Y, Errami AA, Oubaha S, Krati $\mathrm{K}$. The impact of the COVID-19 pandemic on quality of life and well-being in Morocco.2020:1-13.

[3] Hibbi FZ, Abdoun O, El Khatir H. Coronavirus pandemic in Morocco: measuring the impact of containment and improving the learning process in higher education. International Journal of Information and Education Technology. 2021; 11(1):30-4.

[4] Crawford J, Butler-Henderson K, Rudolph J, Malkawi B, Glowatz M, Burton R, et al. COVID-19: 20 countries' higher education intra-period digital pedagogy responses. Journal of Applied Learning \& Teaching. 2020; 3(1):1-20.

[5] Fernández HA. Coronavirus in Arab countries: passing storm, opportunity for change or regional catastrophe. Elcano Real Institute. 2020:1-9.

[6] Al-Baadani AA, Abbas M. The impact of coronavirus (Covid19) pandemic on higher education institutions (HEIs) in Yemen: challenges and recommendations for the future. European Journal of Education Studies. 2020; 7(7):68-82.

[7] Link-Pezet J, Lacombe-Carraud E. Former des formateurs. l'expérience de l'URFIST de Toulouse », Bulletin Des Bibliothèques De France (BBF). 1999:60-9.

[8] Chekour M, Al Achhab M, Laafou M, El Mohajir B. Contribution à l'intégration de l'apprentissage mixte dans le système éducatif marocain. Revue Internationale Des Technologies En Pédagogie Universitaire/International Journal of Technologies in Higher Education. 2014; 11(1):50-60.

[9] Gil PO, García FA. Blended learning revisited: how it brought engagement and interaction into and beyond the classroom. In virtual learning environments: concepts, methodologies, tools and applications 2012 (pp. 52-66). IGI Global.

[10] Tour E. Digital mindsets: Teachers' technology use in personal life and teaching. Language Learning \& Technology. 2015; 19(3):124-39. 
[11] Mayer P, Girwidz R. Physics teachers' acceptance of multimedia applications - adaptation of the technology acceptance model to investigate the influence of TPACK on physics teachers' acceptance behavior of multimedia applications. In frontiers in education 2019 (pp. 1-12). Frontiers.

[12] Chekour M, Laafou M, Janati-Idrissi R. What are the adequate pedagogical approaches for teaching scientific disciplines? Physics as a case study. Journal of Educational and Social Research. 2018; 8(2):141-8.

[13] Kantaria M, Basilaia G, Dgebuadze M, Chokhonelidze G. Applying a new teaching methodology to university programming language courses. International Journal of Education and Research. 2020; 8(4):33-44.

[14] Ehlert A, Schulte C. Empirical comparison of objectsfirst and objects-later. In proceedings of the fifth international workshop on computing education research workshop 2009 (pp. 15-26).

[15] Bruce KB. Controversy on how to teach CS 1: a discussion on the SIGCSE-members mailing list. In working group reports from ITiCSE on Innovation and technology in computer science education 2004 (pp. 29-34).

[16] Fangohr H, O'Brien N, Prabhakar A, Kashyap A. Teaching python programming with automatic assessment and feedback provision. arXiv preprint arXiv:1509.03556. 2015.

[17] Kui X, Liu W, Guo K, Xia J, Du H. Teaching method reform of python language programming course based on minimum knowledge sets. Mechatronic Systems and Control. 2018; 46(4):181-6.

[18] Begosso LC, Begosso LR, Gonçalves EM, Gonçalves JR. An approach for teaching algorithms and computer programming using Greenfoot and Python. In frontiers in education conference proceedings 2012 (pp. 1-6). IEEE.

[19] Jayal A, Lauria S, Tucker A, Swift S. Python for teaching introductory programming: a quantitative evaluation. Innovation in Teaching and Learning in Information and Computer Sciences. 2011; 10(1):8690.

[20] Anouar Tadlaoui M. Management of a learner model in an adaptive education system based on Bayesian networks. PhD Thesis. 2018.

[21] Kui X, Liu W, Xia J, Du H. Research on the improvement of python language programming course teaching methods based on visualization. In international conference on computer science and education 2017 (pp. 639-44). IEEE.

[22] Fagan BJ, Payne B. Learning to program in Pythonby teaching it! Proceedings of the interdisciplinary STEM teaching and learning conference 2017 (pp. 99 107).

[23] Tadlaoui MA, Khaldi M, Carvalho RN, editors. Bayesian networks for managing learner models in adaptive hypermedia systems: emerging research and opportunities: emerging research and opportunities. IGI Global; 2018.
[24] Tadlaoui MA, El Moudden F, Khaldi M. The implementation of a probabilistic learner model in LMS-LD course creation application COPROLINE. International Journal of Advanced Computer Research. 2019; 9(45):386-96.

[25] Tadlaoui MA, Aammou S, Khaldi M, Carvalho RN. Learner modeling in adaptive educational systems: a comparative study. International Journal of Modern Education and Computer Science. 2016; 8(3):1-10.

[26] Tadlaoui MA, Carvalho RN, Khaldi M. A learner model based on multi-entity Bayesian networks and artificial intelligence in adaptive hypermedia educational systems. International Journal of Advanced Computer Research. 2018; 8(37):148-60.

[27] Mouenis AT, AAMMOU S, KHALDI M. Developement of bayesian networks from unified modeling language for learner modelling. International Journal of Ad-Vanced Computer Science and Applications. 2015; 6(2):139-44.

[28] Tadlaoui MA, Carvalho RN, Khaldi M. The initialization of the learner model combining the Bayesian networks and the stereotypes methods. International Journal of Advanced Computer Research. 2017; 7(33):200-12.

[29] Tadlaoui MA, Khaldi M. Personalization and collaboration in adaptive E-learning. IGI Global. 2019.

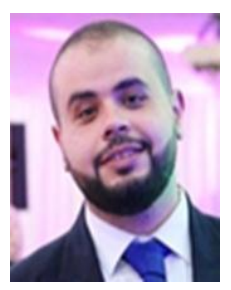

Mouenis Anouar Tadlaoui $\mathrm{PhD}$ in Computer sciences, is a Research Scholar in Computer sciences, at the Laboratory of Informatics, Research Operational and Statistic Applied (LIROSA) at Faculty of Sciences, Abdelmalek Essaadi University. His dissertation research, focus on managing the learner model in Adaptive Hypermedia systems based on Bayesian methods and artificial intelligence. Mouenis Have a Master's degree in Instructional design Multimedia engineering, and a BSc in Web development from Abdelmalek Essaadi University in 2013 \& 2011. He has produced several technical outputs, including Books, Papers, Book Chapters, Technical presentations, among others in the field of Computer Sciences. In research, his current interests include: Learner Modeling, Adaptive Web, Artificial Intelligence, Bayesian Networks and Machine learning.

Email: tadlaouimouenis@gmail.com

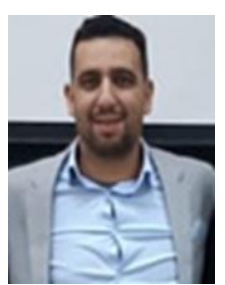

Mohamed Chekour is a PhD Research Scholar in education sciences at Faculty of Sciences, Abdelmalek Essaadi University. His researches focus on the science education and the integration of ICT and simulation in the teaching of the physics concepts.

Email: med.chekour@gmail.com 